\title{
IS THE SELF-REPORT OF DRUG DEPENDENCY RELATED TO INCREASED RATES OF PRIOR OFFENDING AMONG AUSTRALIAN POLICE DETAINEES?
}

\section{A PREPRINT}

\author{
Cameron T. Langfield* \\ Centre for Social Research and Methods \\ Australian National University
}

\author{
Jason L. Payne \\ Centre for Social Research and Methods \\ Australian National University
}

April 8, 2020

\begin{abstract}
Understanding the connection between drug dependency and crime has long occupied the research agendas of both criminologists and public policy experts. However, there remains considerable uncertainty in the empirical literature, in part because different studies operationalise the measurement of drug dependency in different ways. Some, for example, use comprehensive and sophisticated clinical instruments, others use simplified screening tools, while some use single-item self-report measures. Whichever the method, each is an attempt to accurately operationalise the manifestation of drug dependency as an objective trait, yet through their mode of administration, they undoubtedly capture other confounds. The resulting bias can have significant implications for the subsequent estimation of the drug crime relationship, especially if a mode of administration (such as the single-measure self-report) crosses over into other important domains such as personal and social identity. The present study examined the correlation between self-reported drug dependency and crime among a large sample of Australian police detainees who were affirmatively screened for dependency on UNCOPE - a six item clinical screening tool which operationalises dependency as the presence of multiple behavioural and affective experiences of compulsive drug use (Hoffmann, Hunt, Rhodes, \& Riley, 2003; Proctor \& Hoffmann, 2016). Using a mix of descriptive and negative binominal regression techniques, we modelled the frequency of self-reported prior offending in the past 12 months using data from the Drug Use Monitoring in Australia program. After controlling for type, frequency, and longevity of drug use, as well as other demographic factors, we find that those who self-report a drug dependency have higher average rates of prior offending. We argue that these results reflect the social and cultural power of drugdependency identities and the centrality of identity as a third, often unobserved variable in the drug-crime correlation. These result will assist criminologists and criminal justice professionals in further developing interventions to assist drug dependent offenders within the criminal justice system.
\end{abstract}

\section{Introduction}

More than 70 years of drug-crime scholarship has made the academic exploration of the drug-crime nexus one of the most extensively researched empirical phenomena in the social sciences (Anglin \& Speckart, 1988; Becker, 1953; Bennett \& Holloway, 2005a, 2009; Bennett, Holloway, \& Farrington, 2008; Brochu, 2001; Chaiken \& Chaiken, 1990; Donath, 2003; Eddy, Halbach, Isbell, \& Seevers, 1965; Everitt \& Robbins, 2016; Goldstein, 1985; Kornhauser, 2018; McGlothlin, Anglin, \& Wilson, 1978; Payne \& Gaffney, 2012; Reed, 1985; Scheibe, 2017). Stemming from this research, the meta-story is resounding and clear: drug use is higher in criminal populations than the general community (Anglin \& Perrochet, 1998; Chaiken \& Chaiken, 1990; Davison \& Gossop, 1999; Fagan, 1990; Hammersley, Forsyth, Morrison, \& Davies, 1989; Makkai \& Payne, 2003a, 2003b; Parker \& Auerhahn, 1998; Prichard \& Payne, 2005; Voce \& Sullivan, 2019), and those offenders with a dependency on drugs often commit higher frequencies of crime (McIntosh \& McKeganey, 2001; Pierce et al., 2017; Sidwell, Best, \& Strang, 1999; Wagner \& Anthony, 2002). Lastly, we know that those offenders who enter prison with a dependency on drugs commit the

\footnotetext{
${ }^{*}$ Corresponding author: cameron. langfield@anu.edu.au
} 
highest rate of crime post-release, and post-release recidivism is higher still among those offenders who signal an intent to return to drug use (Kinner, 2006).

However, despite the breadth of this empirical work, there is still considerable disagreement about the causal mechanism that underpins the drug-crime nexus (Bean, 2008; Bennett et al., 2008; Seddon, 2000; White \& Gorman, 2000). From the literature, the three most widely supported explanations are that crime causes drug use, that drug use causes crime, and that drug use and crime are caused by a common third variable (see Bennett \& Holloway, 2009; Seddon, 2000 for an overview). While the former two have received the majority of empirical attention (see, for example, Bennett \& Holloway, 2005a; Bennett \& Holloway, 2005b; Bennett et al., 2008; Gizzi \& Gerkin, 2010; Seddon, 2000; White \& Gorman, 2000), the latter has been argued to be the most promising in advancing new avenues for future research (see, for example, Seddon, 2000; White \& Gorman, 2000).

One such area that has gathered recent attention has been the influence of personal and social identity in shaping behavioural continuity (Bamberg, 2011; Burke \& Reitzes, 1981; Howard, 2000; Kiecolt, 1994; Oyserman, 2004; Oyserman, Elmore, \& Smith, 2012; Stryker \& Burke, 2000). Literature on the role of identity in the drug-crime nexus has largely focussed on how individuals rework, reshape, and reform their identity to accommodate both their criminal involvement and their drug use (Dahl, 2015; Dingle, Cruwys, \& Frings, 2015; Earp, Skorburg, Everett, \& Savulescu, 2019; Mackinem \& Higgins, 2008; Neale, Nettleton, \& Pickering, 2011; Reith, 2004). A critical reading of this literature suggests that identity is a powerful mediator of antisocial conduct, including the frequency of both criminal (Hochstetler, DeLisi, \& Puhrmann, 2007; Paternoster, Bachman, Kerrison, O'connell, \& Smith, 2016; Rocque, Posick, \& Paternoster, 2016; Veysey \& Rivera, 2017) and drug using behaviours (Dahl, 2015; Dingle et al., 2015; Kelly, Bergman, \& Vilsaint, 2016; Neale et al., 2011; Reith, 2004; Rocque et al., 2016). Given this, it is our instinct that an individuals' personal and social identities will likely serve as important multipliers of an individual's involvement with both drug use and crime. It is also likely that these identities will influence an individual's engagement with, as well as the outcome of, treatment programs targeted to drug dependent offenders within the criminal justice system (Dingle et al., 2015; Greenfield \& Grella, 2009; Shannon, Jones, Newell, \& Payne, 2018; Welberg, 2011; Werb et al., 2015). Failure to account for identity as an important 'third variable' in the drug-crime relationship may weaken program outcomes which do not tackle identity reformation as a core aspect of treatment.

\subsection{The current study—aims and objectives}

The literature is clear that drug dependency is consistently linked to a higher rate of criminal offending for most drug types and in most contexts. Yet, for those who are screened as dependent according to the Diagnostic and Statistical Manual for Mental Disorders (DSM-V) criteria, what is not clear is whether self-identification is linked to higher or lower rates of criminal involvement. After all, not all those who are screened as dependent actually self-identify (Payne \& Langfield, 2020). Further, this self-identification has been shown to be influenced by both demographic and drug using correlates, with female police detainees and younger drug users more likely to self-report even when the current frequency and longevity of their drug use are held constant (Langfield \& Payne, 2020).

It is here that the current study makes a valuable contribution. Specifically, we exploit archival data from the Drug Use Monitoring in Australia (DUMA) program to explore whether self-reported dependency is independently linked to higher rates of offending among a sample of police detainees who are affirmatively identified as having a substance use disorder according to the DSM-V. For this study, we hypothesise that self-reported dependency will be linked to higher rates of offending, holding constant a detainee's demographic and drug use profile. Should these data evidence significant differences in prior offending among those who are self-identifying as drug dependent, this would strengthen growing calls by scholars (see, for example, Bamberg, 2011; Dahl, 2015; Dingle et al., 2015; Little, 1990; Mackinem \& Higgins, 2008; McIntosh \& McKeganey, 2001; Paternoster \& Bushway, 2009; Rocque et al., 2016; Veysey \& Rivera, 2017) for an identity-focussed exploration of criminal offending in the context of compulsive drug use.

\section{Methodology}

\subsection{Data}

We draw our data from the Australian Institute of Criminology's (AIC) Drug Use Monitoring in Australia (DUMA) program (Patterson, Sullivan, Ticehurst, \& Bricknell, 2018; Voce \& Sullivan, 2019). DUMA is Australia's largest and longest running survey of police detainees (Gannoni \& Goldsmid, 2017) and is the methodological equivalent of the now-defunct US Arrestee Drug Abuse Monitoring Program (ADAM) (U.S. Department of Justice, 2002). Throughout several police Watch-houses across Australia DUMA operates quarterly, and data is gathered over a four-week period. During this time, a census of all detainees is attempted except where access to a detainee is restricted by the Watch-house Sergeant, usually for safety reasons. From each detainee, the data collection procedure gathers official administrative data for the current period of detention, as well as interviewer-administered self-report data on demographics, prior offending and current drug use. At the completion of the 
survey, each detainee is asked to provide a urine specimen for drug testing. Urinalysis is voluntary (Makkai, 1999) and has been a vital tool for the verification of self-reported drug use. The DUMA program has received ethical review clearance by the AIC's Human Research Ethics Committee and the authors' access to this data has been facilitated by the Australian Data Archive with the permission of the AIC.

\subsection{Measures}

The dependent variable of interest in this study is the total number of prior charges a detainee self-reported receiving in the 12 months leading up to their current arrest. Specifically, the DUMA survey asks each detainee "How many charges have you received in the past 12 months?" For the purposes of the current study, self-reported drug-related charges have been excluded from the total count of prior charges.

In this study we are specifically interested in the independent and additive effect of self-identified drug dependency and so we limit the overall sample of this study using two analytical decisions. First, we sample only those police detainees who report using any drug in the past 30 days $(N=14,475)$ and then limit the analysis to those who have been screened by UNCOPE as experiencing DSM-V dependency. This resulted in a final sample of $N=9,431$. See Table 1 for a description of the sampling procedure.

The UNCOPE scale was primarily developed to classify and identify offenders who exhibited behaviours consistent with dysfunctional drug use as defined by the DSM-V criteria for substance use disorders, and triage them for further intervention (Hoffmann et al., 2003) Importantly, the UNCOPE scale has been validated for its internal consistency in detecting drug dependency in criminal justice populations with evidence showing a high reliability (Hoffmann et al., 2003; Proctor \& Hoffmann, 2016). The UNCOPE scale consists of six dichotomous (Y/N) questions which measure the dependency-related behaviours or experiences that are articulated by DSM-V (Payne \& Wong, 2018). Consistent with the coding specifications of UNCOPE (Hoffmann et al., 2003; Proctor \& Hoffmann, 2016), a detainee is classified as drug dependent if they affirm three or more items. The items are: $(\mathrm{U})$ unintended use of drugs, $(\mathrm{N})$ neglecting responsibilities as a result of drug use; $(\mathrm{C})$ wanting to cut down on drug use; $(\mathrm{O})$ having been the subject of others objections about drug use; (P) being preoccupied with thoughts of drug use; and (E) using drugs to alleviate emotional distress or boredom.

To measure the self-report of drug dependency, the DUMA survey asks, "In the previous 12 months, have you felt you needed or were dependent on [DRUG]?" This question is asked for each drug type and the list of drugs include heroin, morphine, cocaine, cannabis, amphetamine, ecstasy, LSD, inhalants, and benzodiazepines. For the purposes of this study, this variable is dichotomous $(0 / 1)$ and a detainee is considered having self-identified if they report 'yes' on any drug type.

Table 1: Sampling selection outcomes

\begin{tabular}{lcc}
\hline & $\mathrm{N}$ & $\%$ \\
\hline Detainees approached (initial sample) & 31,750 & 100.0 \\
Detainees interviewed & 22,474 & 70.1 \\
Detainees who reported any drug use in the past 30 days & 14,475 & 64.4 \\
Detainees who reported any drug use in the past 30 days and screened on UNCOPE (final sample) & 9,431 & 65.2 \\
Detainees self-identified as dependent (\% of final sample) & 6,425 & 68.1 \\
\hline
\end{tabular}

Source: Australian Institute of Criminology - Drug Use Monitoring Australia 2004-2010 [computer file]

Lastly, we condition the analysis on three variables that operationalise a drug using career-specifically, these are the type of drug being used, the frequency of recent use, and the longevity of drug use overall. First, we identified each detainee's drug of primary use (primary drug), which denotes the drug type for which they have the highest frequency of use in the 30 days prior to their most recent arrest. In the small number of cases where a detainee might report the use of two drugs at the same frequency, self-reported dependency was used to classify the primary drug. Detainees who could not be otherwise classified (because they self-reported dependency on two drugs with an equal frequency of use) were then categorised according to the most serious of the drugs they were using. Second, we created a variable which measures self-reported frequency of primary drug use in the past 30 days. This variable measures the number of days of use (range 0 and 30) not the quantity of drug used or number of episodes of use. Finally, we created a variable that measures the longevity of overall drug use for each detainee. For this variable, the number of years of drug use was calculated as the interval between the self-reported age of first drug use and the detainees age at current arrest. This was then categorised into four groups measuring initiation in the last two years, initiation between three and five years ago, initiation between six and 10 years ago, and initiation longer than 10 years ago.

The demographic covariates included in this study were gender (coded 0 for females and 1 for males), age at arrest (coded into 5 groups: 18-25 years, 26-35 years, 36-45 years, 46-55 years and 56+ years), and Indigenous status (coded 0 for non-Indigenous and 1 for Indigenous). 
A PREPRINT - APRIL 8, 2020

Table 2: Descriptive statistics of final sample $(n=14,475)$

\begin{tabular}{|c|c|c|c|c|c|}
\hline & \multicolumn{2}{|c|}{ Self-identifying } & \multicolumn{2}{|c|}{ Not self-identifying } & \multirow{2}{*}{$\begin{array}{c}\text { Total } \\
\text { N }\end{array}$} \\
\hline & $\mathbf{N}$ & $\%$ & $\mathbf{N}$ & $\%$ & \\
\hline Total sample & 6,425 & 68.1 & 3,006 & 31.9 & 9,431 \\
\hline \multicolumn{6}{|l|}{ Age } \\
\hline $18-25$ & 2,569 & 66.7 & 1,281 & 33.3 & 3,850 \\
\hline $26-35$ & 2,626 & 70.9 & 1,079 & 29.1 & 3,705 \\
\hline $36-45$ & 1,052 & 66.3 & 535 & 33.7 & 1,587 \\
\hline $46-55$ & 171 & 62.0 & 105 & 38.0 & 276 \\
\hline $56+$ & 7 & 53.8 & 6 & 46.2 & 13 \\
\hline Male & 5,213 & 67.1 & 2,555 & 32.9 & 7,768 \\
\hline Indigenous & 1,122 & 65.1 & 605 & 34.9 & 1,724 \\
\hline \multicolumn{6}{|c|}{ Frequency of recent drug use } \\
\hline 1-8 days per month & 943 & 41.9 & 1,306 & 58.1 & 2,249 \\
\hline $9-15$ days per month & 789 & 60.8 & 509 & 39.2 & 1,298 \\
\hline 16 or more days per month & 4,693 & 79.8 & 1,191 & 20.2 & 5,884 \\
\hline \multicolumn{6}{|l|}{ Years since first drug use } \\
\hline $0-2$ years & 52 & 40.3 & 77 & 59.7 & 129 \\
\hline $3-5$ years & 353 & 54.3 & 297 & 45.7 & 650 \\
\hline $6-10$ years & 1,524 & 67.2 & 743 & 32.8 & 2,267 \\
\hline $11+$ years & 4,493 & 70.4 & 1,888 & 29.6 & 6,381 \\
\hline \multicolumn{6}{|l|}{ Primary drug of use } \\
\hline Cannabis & 3,503 & 64.3 & 1,945 & 35.7 & 5,448 \\
\hline Speed or ecstasy & 1,390 & 63.4 & 1801 & 36.6 & 2,191 \\
\hline Heroin or morphine & 1,287 & 89.4 & 152 & 10.6 & 1,439 \\
\hline Cocaine & 42 & 46.2 & 49 & 53.8 & 91 \\
\hline Other & 203 & 77.5 & 59 & 22.5 & 262 \\
\hline
\end{tabular}

\subsection{Analytical approach}

The primary objective of this study is to estimate the proportion of UNCOPE screened police detainees who self-identify and to explore whether the self-identification of dependency is related to an increased frequency of prior criminal offending, holding constant their demographics and the frequency, type, and longevity of overall drug use.

Since our dependent variable is an over-dispersed count variable, we employ negative binomial regression modelling for the multivariate analysis. It should be noted that what makes negative binomial regression useful is that the regression model allows the variance of the independent variable - in this case, the number of prior criminal charges - to be larger than its mean, thus more accurately modelling the over-dispersed distribution.

\section{Results}

Of the 9,431 detainees who were screened by UNCOPE as dependent, the majority were non-Indigenous $(81 \%, N=7,707)$ and male $(82 \%, N=7,768)$ (Table 2). Further, the majority of the sample were cannabis users $(57 \%, N=5,448)$, followed by speed/ecstasy users $(23 \%, N=2,191)$, and heroin or other opiate users $(15 \%, N=1,439)$. Overall, 68 percent of detainees in this sample self-identified as being dependent on at least one drug. At the bivariate level, self-identification was highest for heroin and other opiate users $(89 \%)$, and lowest for cocaine users $(46 \%)$. These differences between drug types were statistically significant $\left(\mathrm{X}^{2}=390.66, p<.001\right)$. For frequency of primary drug use, self-identification was most common among high frequency users $\left(X^{2}=1100.1, p<.001\right)$, and lowest for users who had initiated drug use in the last two years $\left(X^{2}=119.32\right.$, $p<.001)$ with a linear relationship observed showing that the longer an individual had been using drugs, the more likely they were to self-identify. Furthermore, women were more likely to self-identify $\left(\mathrm{X}^{2}=21.33, p<.001\right)$, as were younger detainees $\left(X^{2}=24.91, p<.001\right)$ and those who identified as Indigenous Australian $\left(X^{2}=9.01, p<.01\right)$. 
Also, at the bivariate level, detainees who had self-identified as dependent were associated with a higher frequency of prior charges, with a mean difference of one additional charge compared to their dependent peers who did not self-identify. A Kruskal-Wallis H-test confirmed that this was statistically significant $\left(\mathrm{X}^{2}=71.91, p<.001\right)$.

To test the independent effects of each covariate, we use negative binomial regression modelling. In Model 1, we explore the independent effect of self-identification on predicting prior criminal charges. Consistent with the bivariate analysis, we find that self-identifying detainees had a higher frequency of self-reported prior criminal charges. This result was statistically significant $(b=0.38, p<.001)$. In Model 2, this finding remains even when controlling for a detainee's drug use profile $(b=0.26, p<.001)$. Conversely, Model 2 also indicates that the highest frequency drug users reported the highest number of prior criminal charges $(b=0.15, p<.001)$. In terms of drug use longevity, there was no statistically significant difference, although the trend suggests that the longest-term users have the highest rates of recent offending $(b=0.18)$.

Finally, in Model 3, controlling for both drug use and demographics, we find that self-identification remains statistically associated with an increase in self-reported prior criminal charges $(b=0.27, p<.001)$. Of the drug use covariates, a linear relationship is found between the longevity of overall drug use and self-reported prior charges, with longer use now statistically associated with a higher number of prior charges. With respect to the frequency of recent primary drug use, those who had used on 16 days or more in the last 30 were more likely to report a higher number of charges $(b=0.12, p<.001)$. Lastly, a detainee's gender was not statistically related to a higher frequency of prior offending $(b=0.07, p>.05)$, although identifying oneself as an Indigenous Australian was $(b=0.11, p<.001)$.

\section{Discussion}

This study began with a simple objective-to explore whether self-identification as drug dependent was associated with a higher frequency of offending among offenders who are screened as clinically dependent. Our study was motivated by a growing qualitative literature that situates personal identity as an important correlate of behaviour, especially in criminological and drug use research. We offer one of the first large-scale quantitative studies of self-identified drug dependency among a national sample of police detainees and ask whether this self-identification is related to a higher than average frequency of prior offending. We explore whether the result holds in the presence of controls for gender, age, Indigenous status, and drug use career profiles.

Results from the current study indicate that among detainees who have been screened as drug dependent 68 percent selfidentify, and 32 percent do not. Consistent with research elsewhere (Langfield \& Payne, 2020), this was more common among high frequency users, as well as those who had initiated drug use more than 10 years ago. Of interest to the present study, however, is that self-identified drug dependent police detainees were associated with a frequency of prior offending that was 27 percent higher than their non-self-identifying peers; a result that held even after both drug use and demographic profiles were held constant. This is a noteworthy finding and has important implications for the criminal justice system and our efforts to provide evidence-based treatment to drug dependent offenders.

For instance, it is a well-established position in the criminological literature that labelling negative and antisocial behaviours can have deleterious impacts (Baron, 2003; Becker, 1953, 1963; Drapela, 2006; Lloyd, 2013), especially if that labelling profits the development and internalisation of criminal identities (Becker, 1963; Brownfield \& Thompson, 2005; Dahl, 2015; Dingle et al., 2015; Rocque et al., 2016). In addition, identity theorists have long recognised the powerful impact of self-perception and the behaviour which can manifest as a reflection of direct and indirect external appraisals (Brownfield \& Thompson, 2005; Paternoster \& Bushway, 2009; Walters, 2016). In the specific context of the drug-crime relationship, we hypothesised that drug dependency identities would be positively correlated with a higher frequency of offending. We argue that this is either because dependency identities are formed as a technique of neutralisation or because those identities energise action consistent with the social scripts that define dependency-related behaviours-in this case crime. Therefore, it could be that the self-reporting of dependency is not so much about identification with drug use as a 'problem', but rather the adoption or integration of drug use (and crime) as a 'way of life' (Dahl, 2015; Dingle et al., 2015; Leary \& Tangney, 2011; Oyserman et al., 2012). 
Table 3: Negative binomial regression predicting prior criminal charges by self-reported dependency, drug use and demographic profiles

\begin{tabular}{|c|c|c|c|}
\hline & $\begin{array}{l}\text { Model 1: } \\
\text { Self-reported dependency } \\
\text { (coefficient) }\end{array}$ & $\begin{array}{c}\text { Model 2: } \\
\text { Self-reported dependency } \\
\text { + Drug Use (coefficient) }\end{array}$ & $\begin{array}{c}\text { Model 3: } \\
\text { Self-reported dependency } \\
\text { + Drug Use + Demographics } \\
\text { (coefficient) }\end{array}$ \\
\hline \multicolumn{4}{|l|}{ Self-reported dependency } \\
\hline Self-reported (vs. not self-reported) & $0.38 * * *$ & $0.26 * * *$ & $0.27 * * *$ \\
\hline \multicolumn{4}{|l|}{ Years since first use } \\
\hline 3-5 years (vs. 0-2) & - & 0.16 & 0.13 \\
\hline $6-10$ years (vs. $0-2$ ) & - & $0.31 *$ & $0.31 *$ \\
\hline $11+$ years (vs. 0-2) & - & 0.18 & $0.46^{* *}$ \\
\hline \multicolumn{4}{|l|}{ Frequency of recent drug use } \\
\hline 9/15 days (vs. $1 / 8$ days) & - & 0.01 & 0.00 \\
\hline 16 days or more (vs. $1 / 8$ days) & - & $0.15 * * *$ & $0.12 * *$ \\
\hline \multicolumn{4}{|l|}{ Primary drug of use } \\
\hline Cannabis (vs. heroin) & - & $-0.39 * * *$ & $-0.45 * * *$ \\
\hline Speed/ecstasy (vs. heroin) & - & 0.04 & 0.05 \\
\hline Cocaine (vs. heroin) & - & $-0.87 * * *$ & $-0.89 * * *$ \\
\hline Other (vs. heroin) & - & 0.17 & -0.07 \\
\hline \multicolumn{4}{|l|}{ Gender } \\
\hline Male (vs. female) & - & - & 0.07 \\
\hline \multicolumn{4}{|l|}{ Age Group } \\
\hline $26-35$ (vs. 18-25) & - & - & $-0.31 * * *$ \\
\hline $36-45$ (vs. 18-25) & - & - & $-0.56 * * *$ \\
\hline 46-55 (vs. 18-25) & - & - & $-0.64 * *$ \\
\hline $56+($ vs. 18-25) & - & - & -0.47 \\
\hline \multicolumn{4}{|l|}{ Indigenous status } \\
\hline Indigenous (vs. non-Indigenous) & - & - & $0.11 * *$ \\
\hline Constant & $1.10 * * *$ & $1.08 * * *$ & $1.08 * * *$ \\
\hline $\mathrm{N}$ & 9,431 & 9,427 & 9,426 \\
\hline Log Likelihood & -21957.863 & -21870.032 & -21814.225 \\
\hline $\begin{array}{l}\text { Chi Square } \\
*=p<.05 ; * * p<.01 ; * * * p<.001\end{array}$ & $X 2(1)=98.56, p=0.00$ & $X 2(10)=266.68, p=0.00$ & $\mathrm{X} 2(16)=368.36, p=0.00$ \\
\hline Source: Australian Institute of Crir & ogy - Drug Use Monitori & Australia 2004-2010 [co & file] \\
\hline
\end{tabular}


Of course, we recognise that our data cannot establish the extent or direction of causality here-a challenge faced by most cross-sectional studies of identity and crime. Nevertheless, the statistical evidence presented here of a correlation between selfidentification and higher rates of crime is important and should inform the cognitive behavioural parameters of those treatment programs that are offered in the context of criminal justice contact and monitoring. More specifically, these data suggest that drug treatment programs which focus on drug type, frequency, or longevity as the only key parameters risk ignoring entrenched drug use identities which are an important and potentially powerful correlate of past and future criminal offending.

At this juncture, it is worth noting that a drug dependency identity, while statistically significant, was not the only factor to predict higher frequencies of offending among these Australian police detainees. Indeed, users of heroin, amphetamine, ecstasy, and other opiates had the highest overall rates of prior offending, and their recent offending was significantly higher than was reported by their cannabis, cocaine, and other drug using peers. These between-drug effects remained significant even when the effect of self-identification was held constant. Similarly, the frequency of recent drug use was also a significant predictor of more frequent offending and, again, this correlation persisted in the presence of controls for dependency identity. The point we emphasise here is threefold. First, our data exhibit correlations that are consistent with much of the existing drug-crime literature. Specifically, our study confirms that different drug types and higher frequencies of drug use are related to higher rates of offending. This is not a surprising finding, although it is pleasing to see this replication confirmed. Second, even in the presence of these strong correlates, the variable measuring identity was statistically significant. As scholars of the interactionist perspective might suggest, this result affirms a powerful link between the 'who I am' and the 'what I do' even if the direction of causality cannot be established. Finally, we note that while identity is important here in these data, it isn't the only correlate and it does not explain away the power of drug type or the frequency of drug use as predictors of offending. Drug use identities are an important part of the drug-crime story, but not the only part.

Finally, while it was not the primary objective of this study to explore the demographic correlates of crime among a sample of drug dependent offenders, it is worth nothing the results of these correlations. Age, for example, was a strong and statistically significant correlate of recent crime frequency. Consistent with decades of research on the age-crime curve (see Loeber \& Farrington, 2014), younger offenders committed more crime in the past 12 months. What makes this finding particularly notable is that the ever-present age-crime relationship holds in a sample of drug dependent offenders and even in a model which controls for the type and frequency of drug use, as well as one's drug dependency identity. Gender on the other hand was not statistically significant in this drug dependent sample, while Indigenous offenders reported higher rates of prior offending.

\subsection{Policy implications}

From these results emerge a number of important implications for policy and practice. First, those drug dependent offenders who identify with their dependency have higher rates of recent offending. Whether the identity has manifested as a consequence of this more prolific offending, or is the cause of it, remains to be seen. In any case, these data serve as an important reminder that efforts to curb drug-related crime must factor in the power of identity as an important correlate. This is especially important for drug treatment programs that are embedded into the criminal justice system and suggests that best-practice treatment must account for the potential that behavioural continuity results from the internalisation of a strong drug using identity. Whereas traditional cognitive behavioural interventions might target environmental cues and triggers for drug use and criminal relapse, it appears equally important that there be dedicated work on identity transformation as a core feature of the cognitive change process. Specifically, interventions targeted to individuals who self-identify as drug dependent will likely be most effective when an identity 'deactivation' process has been initiated (Bachman, Kerrison, Paternoster, O'Connell, \& Smith, 2016), whereby an individual's 'drug using identity' can be changed and deemphasised with respect to its influence on the individuals' behaviour.

Second, it is worth noting around 30 percent of drug dependent offenders did not identify themselves as dependent. While these offenders had lower rates of prior offending, they were by no means inactive in their criminal participation and are equally likely to need drug treatment. What matters here is that this sizable group of offenders do not see themselves as dependent and are likely to be less motivated to redress their drug use. Some of these offenders may not receive treatment if they are unwilling to volunteer their participation, which is their right. However, some will end up on treatment programs motivated not by the desire to change their drug use (which they don't currently see as a problem) but by the desire to avoid more serious sanctions. Drug courts have long struggled with the idea that drug treatment is a coercive practice that (sometimes) encourages offenders to perform treatment without a genuine motivation for change. Further, there is a risk that mandating treatment to those who have not yet come to identify with a 'drug dependent identity' may, in fact, offer differential association environments (see Gray, Durkin, Call, Evans, \& Melton, 2015) which further exacerbate, or 'escalate' the internalisation of this 'drug using' identity - the very objective these interventions aim to prevent.

\subsection{Limitations and future research}

In drawing this study to a close, we are compelled to point out to our readers that in our final model, the Pseudo- $\mathrm{R}^{2}$ was estimated at $R^{2}=0.01$. While the Pseduo- $R^{2}$ of a negative binomial model does not carry the same meaning as in a linear 
regression, it is nevertheless important to emphasise here just how little of the variance in offending we have explained in this study. Clearly, while drug use identities are a statistically significant predictor of higher levels of offending, the predictive power of a dichotomously operationalised measure of dependency identity is, at best, weak. In part, we believe that this reflects the limited measurement options available in these secondary data and future research would need to tease out the true nature of a drug dependency identity with a more sophisticated measurement instrument. We would add here that the final model also includes the type of drug used, the frequency of recent use, and several demographic correlates and yet, still, the degree of variance explained is low. In some respects, we are not surprised by this result-after all, drug-crime research has largely failed to demonstrate a strong causal model leading many criminologists and criminal justice practitioners to conclude that criminality is not so much a function of drug use or drug dependency, but is a function of a complex mix of socially conditioned interactions and systems of mutual causality.

Finally, our reliance on self-report data for both drug use, drug dependency, and prior offending is an important limitation worth noting. For the obvious reasons, these data are affected by a potentially strong social desirability effect, especially since the collection of this information occurs in a police watch-house. The more important implication is the potential that our results are confounded by a strong latent propensity to self-report (or not) which drives the subsequent correlations we see in these data. Perhaps those who are willing to self-identify as drug dependent are also more likely to self-report their rate of offending with greater honesty and accuracy. In other work using these same DUMA data, honesty in self-reported drug use was shown to be highest among those with the most entrenched drug use problems (McGregor \& Makkai, 2003). The argument offered by those authors was that serious drug users are often more experienced in their contact with the criminal justice system and are less worried about the legal consequences of telling the truth about their behaviour. For our study, it is important to recognise that at least some of the statistical correlation seen in these data may be the result of an underlying propensity to self-report (see also Payne \& Piquero, 2016). We would add that this is a wider problem that exists with all tests of identity theory-it is difficult to parse the true correlation between identity and behaviour, when the self-report of both measures is correlated for other underlying reasons. Future work is needed to disentangle this complex web, especially if we are to improve our understanding of the true link between identity, drug use, and drug-related crime.

\section{References}

Anglin, M. D., \& Perrochet, B. (1998). Drug use and Crime: A Historical Review of Research Conducted by the UCLA Drug Abuse Research Center. Substance Use \& Misuse, 33(9), 1871-1914. doi: 10.3109/10826089809059325

Anglin, M. D., \& Speckart, G. (1988). Narcotics and Crime: A Multisample, Multimethod Analysis Criminology, 26(2), 197-233. doi: 10.1111/j.1745-9125.1988.tb00839.x

Bachman, R., Kerrison, E., Paternoster, R., O'Connell, D., \& Smith, L. (2016). Desistance for a Long-Term Drug-Involved Sample of Adult Offenders: The Importance of Identity Transformation. Criminal Justice and Behavior, 43(2), 164-186. doi: $10.1177 / 0093854815604012$

Bamberg, M. (2011). Who am I? Narration and its contribution to self and identity. Theory \& Psychology, 21(1), 3-24. doi: $10.1177 / 0959354309355852$

Baron, S. W. (2003). Self-Control, Social Consequences, and Criminal Behavior: Street Youth and the General Theory of Crime. Journal of Research in Crime and Delinquency, 40(4), 403-425. doi: 10.1177/0022427803256071

Bean, P. (2008). Drugs and Crime (3rd Edition ed.). Devon: Willan Publishing.

Becker, H. S. (1953). Becoming a Marihuana User. American Journal of Sociology, 59(3), 235-242. doi: 10.1086/221326

Becker, H. S. (1963). Outsiders: Studies in the Sociology of Deviance. Art Worlds (Berkeley).

Bennett, T., \& Holloway, K. (2005a). The association between multiple drug misuse and crime. International Journal of Offender Therapy and Comparative Criminology, 49(1), 63-81.

Bennett, T., \& Holloway, K. (2005b). Disaggregating the Relationship between Drug Misuse and Crime. Australian and New Zealand Journal of Criminology, The, 38(1), 102-121. doi: 10.1375/acri.38.1.102

Bennett, T., \& Holloway, K. (2009). The Causal Connection Between Drug Misuse and Crime. The British Journal of Criminology, 49(4), 513-531. doi: 10.1093/bjc/azp014

Bennett, T., Holloway, K., \& Farrington, D. (2008). The statistical association between drug misuse and crime: A meta-analysis. Aggression and Violent Behavior, 13(2), 107-118. doi: 10.1016/j.avb.2008.02.001

Brochu, S. (2001). The Relationship Between Drugs and Crime. Montreal: University of Montreal. Brownfield, D., \& Thompson, K. (2005). Self-Concept and Delinquency: The Effects of Reflected Appraisals by Parent and Peers. Western Criminology Review, 6(1). 
Burke, P. J., \& Reitzes, D. C. (1981). The Link Between Identity and Role Performance. Social Psychology Quarterly, 44(2), 83-92. doi: 10.2307/3033704

Chaiken, J. M., \& Chaiken, M. R. (1990). Drugs and Predatory Crime. Crime and Justice, 13, 203-239. doi: 10.1086/449176

Dahl, S. L. (2015). Remaining a user while cutting down: The relationship between cannabis use and identity. Drugs: Education, Prevention and Policy, 22(3), 175-184. doi: 10.3109/09687637.2014.920765

Davison, S. E., \& Gossop, M. (1999). The Management of Opiate Addicts in Police Custody. Medicine, Science and the Law, 39(2), 153-160. doi: 10.1177/002580249903900210

Dingle, G. A., Cruwys, T., \& Frings, D. (2015). Social Identities as Pathways into and out of Addiction. Frontiers in psychology, 6, 1795-1795. doi: 10.3389/fpsyg.2015.01795

Donath, S. (2003). Women and drugs. In A. Ritter, T. King \& M. A. Hamilton (Eds.), Drug use in Australia: preventing harm: Oxford University Press.

Drapela, L. A. (2006). The Effect of Negative Emotion on Licit and Illicit Drug Use Among High School Dropouts: An Empirical Test of General Strain Theory. Journal of Youth and Adolescence, 35(5), 752-767. doi: 10.1007/s10964-006-9059-0

Earp, B. D., Skorburg, J. A., Everett, J. A. C., \& Savulescu, J. (2019). Addiction, Identity, Morality. AJOB Empirical Bioethics, 10(2), 136-153. doi: 10.1080/23294515.2019.1590480

Eddy, N. B., Halbach, H., Isbell, H., \& Seevers, M. H. (1965). Drug dependence: its significance and characteristics. Bulletin of the World Health Organization, 32(5), 721-733.

Everitt, B. J., \& Robbins, T. W. (2016). Drug Addiction: Updating Actions to Habits to Compulsions Ten Years On. Annual Review of Psychology, 67(1), 23-50. doi: 10.1146/annurev-psych-122414-033457

Fagan, J. (1990). Intoxication and aggression. In M. T. J. Q. Wilson (Ed.), Drugs and Crime (Crime and justice: a review of the research) (Vol. 13). Chicago: University of Chicago Press.

Gannoni, A., \& Goldsmid, S. (2017). Readiness to change drug use and help-seeking intentions of police detainees : findings from the DUMA program. Trends and Issues in Crime and Criminal Justice(520), 1-17.

Gizzi, M. C., \& Gerkin, P. (2010). Methamphetamine use and criminal behavior. Int J Offender Ther Comp Criminol, 54(6), 915-936. doi: 10.1177/0306624x09351825

Goldstein, P. J. (1985). The Drugs/Violence Nexus: A Tripartite Conceptual Framework. Journal of Drug Issues, 15(4), 493506. doi: $10.1177 / 002204268501500406$

Gray, A. C., Durkin, K. F., Call, J. T., Evans, H. J., \& Melton, W. (2015). Differential association and marijuana use in a juvenile drug court sample [Electronic Version]. Applied Psychology in Criminal Justice, 11(1), 1-8.

Greenfield, S. F., \& Grella, C. E. (2009). Alcohol \& Drug Abuse: What Is "Women-Focused" Treatment for Substance Use Disorders? Psychiatric Services, 60(7), 880-882. doi: 10.1176/ps.2009.60.7.880

Hammersley, R., Forsyth, A., Morrison, V., \& Davies, J. B. (1989). The Relationship Between Crime and Opioid Use. British Journal of Addiction, 84(9), 1029-1043. doi: 10.1111/j.1360-0443.1989.tb00786.x

Hochstetler, A., DeLisi, M., \& Puhrmann, A. M. (2007). Toward an Integrated Model of Offending Frequency: A Replication Study. Justice Quarterly, 24(4), 582-599. doi: 10.1080/07418820701717128

Hoffmann, N. G., Hunt, D. E., Rhodes, W. M., \& Riley, K. J. (2003). UNCOPE: A Brief Substance Dependence Screen for Use with Arrestees. Journal of Drug Issues, 33(1), 29-44. doi: 10.1177/002204260303300102

Howard, J. (2000). Social Psychology of Identities. Annual Review of Sociology, 26(1), 367-393. doi: 10.1146/annurev.soc.26.1.367

Kelly, J. F., Bergman, B. G., \& Vilsaint, C. L. (2016). Addiction recovery, mutual-help organizations and social identity Addiction, Behavioral Change and Social Identity (pp. 46-63): Routledge.

Kiecolt, K. J. (1994). Stress and the Decision to Change Oneself: A Theoretical Model. Social Psychology Quarterly, 57(1), 49-63. doi: $10.2307 / 2786974$

Kinner, S. (2006). The post-release experience of prisoners in Queensland: Australian Institute of Criminology Canberra.

Kornhauser, R. (2018). The effectiveness of Australia's drug courts. Australian and New Zealand Journal of Criminology, The, 51(1), 76-98. doi: 10.1177/0004865816673412 
Langfield, C. T., \& Payne, J. L. (2020, Feburary 28). What factors predict the self-identification of drug dependency among criminal justice populations? Prevalence, correlates, and implications for the criminal justice system. doi: https://doi.org/10.31235/osf.io/b7cjp

Leary, M. R., \& Tangney, J. P. (2011). Handbook of self and identity: Guilford Press.

Little, M. (1990). Young men in prison: The criminal identity explored through the rules of behaviour: Dartmouth Aldershot.

Lloyd, C. (2013). The stigmatization of problem drug users: A narrative literature review. Drugs: Education, Prevention and Policy, 20(2), 85-95. doi: 10.3109/09687637.2012.743506

Loeber, R., \& Farrington, D. P. (2014). Age-crime curve. In G. B. D. Weisburd (Ed.), Encyclopedia of Criminology and Criminal Justice (pp. 12-18).

Mackinem, M. B., \& Higgins, P. (2008). Drug court; constructing the moral identity of drug offenders (Vol. 23). Portland: Ringgold, Inc.

Makkai, T. (1999). Drug use monitoring in Australia (DUMA): a brief description (Vol. no.21.). Canberra: Australian Institute of Criminology.

Makkai, T., \& Payne, J. L. (2003a). Drugs and Crime: A study of incarcerated male offenders. Canberra: Australian Institute of Criminology.

Makkai, T., \& Payne, J. L. (2003b). Key Findings from the Drug Use Careers of Offenders (DUCO) Study. Trends \& Issues in Crime \& Criminal Justice.

McGlothlin, W. H., Anglin, M. D., \& Wilson, B. D. (1978). Narcotic Addiction and Crime. Criminology, 16(3), 293-315. doi: 10.1111/j.1745-9125.1978.tb00094.x

McGregor, K., \& Makkai, T. (2003). Self-reported Drug Use: How Prevalent is Under-reporting? Trends \& Issues in Crime \& Criminal Justice, No. 260. Canberra: Australian Institute of Criminology.

McIntosh, J., \& McKeganey, N. (2001). Identity and Recovery from Dependent Drug Use: the addict's perspective. Drugs: Education, Prevention and Policy, 8(1), 47-59. doi: 10.1080/09687630124064

Neale, J., Nettleton, S., \& Pickering, L. (2011). Recovery from problem drug use: What can we learn from the sociologist Erving Goffman? Drugs: Education, Prevention and Policy, 18(1), 3-9. doi: 10.3109/09687631003705546

Oyserman, D. (2004). Self-concept and Identity Self and social identity. (pp. 5-24). Malden: Blackwell Publishing.

Oyserman, D., Elmore, K., \& Smith, G. (2012). Self, self-concept, and identity. In M. L. J. Tangney (Ed.), Handbook of Self and Identity. New York: The Guilford Press.

Parker, R. N., \& Auerhahn, K. (1998). Alcohol, Drugs, and Violence. Annual Review of Sociology, 24(1), 291-311. doi: 10.1146/annurev.soc.24.1.291

Paternoster, R., Bachman, R., Kerrison, E., O'connell, D., \& Smith, L. (2016). Desistance from Crime and Identity:An Empirical Test With Survival Time. Criminal Justice and Behavior, 43(9), 1204-1224. doi: 10.1177/0093854816651905

Paternoster, R., \& Bushway, S. (2009). Desistance and the "feared self": toward an identity theory of criminal desistance. The Journal of Criminal Law and Criminology (1973-), 99(4), 1103-1156.

Patterson, E., Sullivan, T., Ticehurst, A., \& Bricknell, S. (2018). Drug use monitoring in Australia: 2015 and 2016 report on drug use among police detainees. Canberra: Australian Institute of Criminology.

Payne, J. L., \& Gaffney, A. (2012). How much crime is drug or alcohol related? Self-reported attributions of police detainees. Trends and Issues in Crime and Criminal Justice [electronic resource](439), 1-6.

Payne, J. L., \& Langfield, C. T. (2020, February 19). When two measures of drug dependency do not accord: prevalence, correlates, and implications for treatment in the criminal justice context [pre-print]. doi: https://doi.org/10.31235/osf.io/tz2ax

Payne, J. L., \& Piquero, A. R. (2016). The concordance of self-reported and officially recorded lifetime offending histories: Results from a sample of Australian prisoners. Journal of Criminal Justice, 46, 184-195. doi: https://doi.org/10.1016/j.jcrimjus.2016.05.004

Payne, J. L., \& Wong, G. (2018). Measuring drug dependence in police custody: An item response theory and differential item function analysis of UNCOPE in Australia. Drug and Alcohol Review, 37(7), 856-864. doi: 10.1111/dar.12854 
Pierce, M., Hayhurst, K., Bird, S. M., Hickman, M., Seddon, T., Dunn, G., \& Millar, T. (2017). Insights into the link between drug use and criminality: Lifetime offending of criminally-active opiate users. Drug and Alcohol Dependence, 179, 309-316. doi: 10.1016/j.drugalcdep.2017.07.024

Prichard, J., \& Payne, J. L. (2005). Key findings from the Drug Use Careers of Juvenile Offenders study. Canberra: Australian Institute of Criminology. Retrieved from https://aic.gov.au/publications/tandi/tandi304.

Proctor, S. L., \& Hoffmann, N. G. (2016). The UNCOPE: An effective brief screen for DSM-5 substance use disorders in correctional settings. Psychology of addictive behaviors : journal of the Society of Psychologists in Addictive Behaviors, 30(5), 613-618. doi: 10.1037/adb0000170

Reed, B. G. (1985). Drug Misuse and Dependency in Women: The Meaning and Implications of Being Considered a Special Population or Minority Group. International Journal of the Addictions, 20(1), 13-62. doi: 10.3109/10826088509074828

Reith, G. (2004). Consumption and its discontents: Addiction, identity and the problems of freedom. The British journal of sociology, 55(2), 283-300.

Rocque, M., Posick, C., \& Paternoster, R. (2016). Identities Through Time: An Exploration of Identity Change as a Cause of Desistance. Justice Quarterly, 33(1), 45-72. doi: 10.1080/07418825.2014.894111

Scheibe, L. (2017). Visualising "junkies" and "meth heads" - a visual analysis of the persistent negative reputation of heroin and meth users. Drugs and Alcohol Today, 17(1), 40-49. doi: 10.1108/DAT-11-2016-0027

Seddon, T. (2000). Explaining the Drug-Crime Link: Theoretical, Policy and Research Issues. Journal of Social Policy, 29(1), 95-107. doi: 10.1017/S0047279400005833

Shannon, L. M., Jones, A. J., Newell, J., \& Payne, C. (2018). Examining Individual Characteristics and Program Performance to Understand Two-Year Recidivism Rates Among Drug Court Participants: Comparing Graduates and Terminators. International Journal of Offender Therapy and Comparative Criminology, 62(13), 4196-4220. doi: 10.1177/0306624x18769602

Sidwell, C., Best, D., \& Strang, J. (1999). Cost of drug use and criminal involvement before and during methadone treatment. Journal of Clinical Forensic Medicine, 6(4), 224-227. doi: https://doi.org/10.1016/S1353-1131(99)90001-9

Stryker, S., \& Burke, P. J. (2000). The Past, Present, and Future of an Identity Theory. Social Psychology Quarterly, 63(4), 284-297. doi: 10.2307/2695840 U.S. Department of Justice. (2002). I-ADAM in Eight Countries: Approaches and Challenges. Washington, D.C.: U.S. Department of Justice Retrieved from https://www.ncjrs.gov/pdffiles1/nij/189768.pdf.

Veysey, B., \& Rivera, L. (2017). Implicit Criminal Identity and Age: Implications for Criminal Persistence and Desistance. Criminal Justice and Behavior, 44(10), 1249-1261. doi: 10.1177/0093854817722173

Voce, A., \& Sullivan, T. (2019). Drug use monitoring in Australia: Drug use among police detainees, 2018. Canberra: Australian Institute of Criminology Retrieved from https://aic.gov.au/publications/sr/sr18.

Wagner, F. A., \& Anthony, J. C. (2002). From first drug use to drug dependence; developmental periods of risk for dependence upon marijuana, cocaine, and alcohol. Neuropsychopharmacology: official publication of the American College of Neuropsychopharmacology, 26(4), 479. doi: 10.1016/S0893-133X(01)00367-0

Walters, G. D. (2016). Reflected appraisals and self-view in delinquency development: An analysis of retrospective accounts from members of the Racine birth cohorts. Journal of Criminal Justice, 47, 100-107. doi: https://doi.org/10.1016/j.jcrimjus.2016.07.004

Welberg, L. (2011). Addiction: from mechanisms to treatment. Nature Reviews Neuroscience, 12(11), 621-621. doi: $10.1038 / \mathrm{nrn} 3131$

Werb, D., Kamarulzaman, A., Meacham, M. C., Rafful, C., Fischer, B., Strathdee, S. A., \& Wood, E. (2015). The effectiveness of compulsory drug treatment: A systematic review. International Journal of Drug Policy, 28, 1-9. doi: 10.1016/j.drugpo.2015.12.005

White, H. R., \& Gorman, D. M. (2000). Dynamics of the drug-crime relationship. Criminal justice, 1(15), 1-218. 